\title{
PENGARUH PEMANGKASAN TERHADAP PRODUKSI TUNAS PADA KEBUN PANGKAS BIDARA LAUT
}

\section{(Strychnos lucida R Brown) The Effect of Hedging to The Production of Shoots on The Hedge Orchard of Strychnos lucida R Brown}

\author{
Anita Apriliani Dwi Rahayu ${ }^{1} \&$ Krisnawati ${ }^{2}$ \\ ${ }^{1,2}$ Balai Penelitian dan Pengembangan Teknologi Hasil Hutan Bukan Kayu \\ Jl. Dharma Bhakti No. 7, Ds. Langko, Kec. Lingsar, Lombok Barat - NTB 83371 \\ Telp. (0370) 6175552, Fax. (0370) 6175482

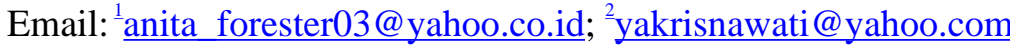

\begin{abstract}
Bidara laut (Strychnos lucida $R$ Brown) is a potential of traditional medicinal plant, especially in the area of $B$ ali and NTB. Efficacy of $\mathrm{S}$. lucida wood is used to malaria medicine and stamina enhancer. One way to ensure the supply of raw material of S. lucida, need to be cultivated as plant propagation by cuttings. Vegetative propagation of plants using shoot cuttings needs juvenile plant material. One of way to get it is build the hedge orchard. Hedging techniques are necessary aspect on hedge orchard management whose role is to determine the productivity and quality of the cutting materials. This study aims to determine the effect of stock plant height after hedging $(10 \mathrm{~cm}$ and $20 \mathrm{~cm})$ to the production of shoots. The study design used completely randomized design. The parameters measured were the number of shoots and length of shoot after four months of observation. The results showed that the difference of stock plant height of $\mathrm{S}$. lucida after hedging affects the number of shoots which has significant number at 0.001, while height of hedging was not significant (>0.05). After four months, height of hedging of $20 \mathrm{~cm}$ produced more shoots than height of hedging of $10 \mathrm{~cm}$ at 2.59 shoots.
\end{abstract}

Keywords: Strychnos lucida R. Brown, hedging, the production of shoots, hedge orchard

\begin{abstract}
ABSTRAK
Bidara laut (Strychnos lucida R Brown) merupakan tumbuhan obat tradisional yang potensial, khususnya di wilayah Bali dan NTB. Khasiat kayu bidara laut antara lain digunakan sebagai obat malaria dan penambah stamina. Salah satu cara untuk menjamin pasokan bahan baku kayu bidara laut, perlu dilakukan budidaya seperti perbanyakan tanaman dengan stek. Perbanyakan tanaman secara vegetatif menggunakan stek pucuk memerlukan bahan tanaman yang juvenil. Salah satu cara untuk mendapatkannya yaitu dengan membangun kebun pangkas. Teknik pemangkasan merupakan aspek yang diperlukan dalam pengelolaan kebun pangkas yang berperan untuk menentukan produktivitas dan kualitas bahan stek. Penelitian ini bertujuan untuk mengetahui pengaruh tinggi tanaman induk setelah pemangkasan $(10 \mathrm{~cm}$ dan $20 \mathrm{~cm})$ terhadap produksi tunas. Rancangan penelitian menggunakan Rancangan Acak Lengkap. Parameter yang diukur adalah jumlah tunas dan panjang tunas setelah 4 bulan pengamatan. Hasil penelitian menunjukkan bahwa perbedaan tinggi tanaman induk bidara laut setelah pemangkasan mempengaruhi jumlah tunas yang dihasilkan dengan nilai signifikansi 0,001, sedangkan panjang tunas tidak signifikan $(>0,05)$. Setelah 4 bulan pemangkasan, tinggi pangkasan 20 $\mathrm{cm}$ menghasilkan tunas yang lebih banyak dibandingkan tinggi pangkasan $10 \mathrm{~cm}$ yaitu 2,59 tunas.
\end{abstract}

Kata Kunci : Strychnos lucida R Brown, pemangkasan, produksi tunas, kebun pangkas

\section{A. PENDAHULUAN}

Bidara laut atau songga (Strychnos lucida $\mathrm{R}$ Brown) merupakan tumbuhan obat tradisional yang potensial, khususnya di wilayah Bali dan NTB. Hampir semua bagian tanaman bidara laut dapat dimanfaatkan 
sebagai obat yaitu bagian kulit kayu, akar, biji dan batang/kayunya (Wahyuni, 2014). Berdasarkan hasil penelitian Hasan, Nandini \& Wahyuni (2011), kulit kayu adalah bagian tanaman yang banyak mengandung khasiat obat. Khasiat kayu bidara laut antara lain digunakan sebagai obat malaria dan penambah stamina (Waluyo \& Marlena, 1992).

Penggunaan kayu bidara laut untuk obat tradisional sudah mulai dijadikan peluang usaha. Hal tersebut menyebabkan keberadaan pohon bidara laut di alam sudah langka. Sasaran masyarakat yaitu batang bidara laut, sehingga menebang habis menjadi kebisaaan masyarakat dalam mengambil kayu bidara laut di alam. Kayu dibentuk menjadi gelas/cangkir yang biasanya digunakan sebagai suvenir dan air yang dimasukkan ke dalam gelas tersebut akan memiliki khasiat obat (Hasan et al., 2011; Zuraida, Sukito, \& Darmawan, 2012). Usaha gelas bidara laut ini tidak hanya memenuhi kebutuhan dalam negeri, akan tetapi sudah diekspor ke Malaysia, Hong Kong dan Singapura. Nilai ekonomi yang tinggi ini menyebabkan eksploitasi jenis ini di kawasan hutan menjadi berlebihan (Zuraida et al., 2012).

Salah satu cara untuk menjamin pasokan bahan baku kayu bidara laut adalah perlu dilakukannya perbanyakan atau budidaya. Budidaya dapat dilakukan secara generatif dan vegetatif. Perbanyakan vegetatif yang sering dilakukan adalah dengan stek.

Perbanyakan tanaman secara vegetatif menggunakan stek pucuk memerlukan bahan tanaman yang juvenil. Bahan tanaman yang juvenil atau bagian stek yang selalu muda terletak di bagian pucuk tanaman. (Hidayat \& Nurochman 2016). Salah satu cara untuk mendapatkannya yaitu dengan dibangunnya kebun pangkas (Pudjiono, 2014). Dengan pembangunan kebun pangkas sebagai sumber bahan stek maka akan didapatkan tunas secara terus menerus.

Teknik pemangkasan merupakan aspek yang diperlukan dalam pengelolaan kebun pangkas yang berperan untuk menentukan produktivitas dan kualitas bahan stek (Pramono \& Danu, 2013). Secara umum, pemangkasan pada bagian atas tanaman akan menstimulasi tumbuhnya tunas-tunas baru. Pemangkasan tanaman di kebun pangkas dilakukan guna mendapatkan tunas-tunas yang orthotrop dan juvenil sebagai materi untuk perbanyakan vegetatif (stek). Pemangkasan mampu meningkatkan jumlah tunas yang tumbuh (Pramono \& Danu, 2013). Pada usia dua minggu setelah pemangkasan dilakukan, biasanya akan muncul bakal tunas pada mata tunas yang dorman (Sulaeman, 2013).

Beberapa faktor yang dapat mempengaruhi munculnya tunas adalah umur tanaman, ukuran tanaman, dan faktor lingkungan (Kijkar, 1991 dalam Putri \& Ristiyana, 2006). Semakin tua kebun pangkas, maka produksi steknya semakin tinggi akan tetapi kemampuan berakarnya akan semakin rendah (Priadjati, Smits, \& Tolkamp, 2001). Oleh karena itu, diperlukan pemangkasan pada pembangunan kebun pangkas bidara laut guna mendapatkan materi stek untuk perbanyakan. Penelitian ini bertujuan untuk mengetahui produksi tunas dari pemangkasan tinggi $10 \mathrm{~cm}$ dan $20 \mathrm{~cm}$.

\section{BAHAN DAN METODE}

\section{A. Lokasi dan Waktu}

Penelitian dilaksanakan di persemaian Kawasan Hutan Dengan Tujuan Khusus (KHDTK) Rarung, Pringgarata, Kabupaten Lombok Tengah, NTB. Kegiatan penelitian dilakukan pada bulan Juni sampai dengan Desember 2015.

\section{B. Bahan dan Alat}

Sedangkan untuk peralatan yang digunakan yaitu polibag, paranet, plastic sungkup, kawat, bambu, gunting stek, penggaris, alat tulis dan kamera.

\section{Prosedur Kerja}

1. Bibit yang telah disiapkan sebelumnya dipindahkan ke polibag dengan media tanah dan pupuk kandang pada komposisi 1:1. Sebelum dilakukan pemangkasan, bibit diukur tinggi dan diameternya. 
2. Satu minggu setelah penyapihan, bibit dipangkas menggunakan gunting stek. Semua cabang dan daun dipotong, sedangkan batang utama dipotong setinggi $10 \mathrm{~cm}$ dan $20 \mathrm{~cm}$ dari permukaan tanah dalam polibag.

3. Setelah pemangkasan, bibit di dalam polibag diletakkan di bedeng-bedeng persemaian. Untuk menjaga kelembaban agar tetap stabil, setiap bedeng ditutup dengan sungkup plastik. Keseluruhan bedeng persemaian di tutup paranet yang berfungsi untuk mengurangi intensitas cahaya dan menjaga suhu tidak terlalu tinggi.

4. Parameter yang diamati adalah jumlah dan panjang tunas pada umur 4 bulan setelah pemangkasan. Jumlah tunas didapatkan dengan menghitung tunas yang muncul pada masing-masing stek. Panjang tunas didapatkan dengan mengukur rata-rata panjang tunas pada tiap stek.

\section{Rancangan Penelitian}

Kegiatan penelitian menggunakan Rancangan Acak Lengkap dengan 2 perlakuan yaitu pemangkasan pada ketinggian $10 \mathrm{~cm}$ dan $20 \mathrm{~cm}$. Setiap perlakuan pemangkasan terdiri dari 264 tanaman. Parameter yang diukur adalah jumlah tunas dan panjang tunas.

\section{B. Analisis Data}

Data yang didapatkan diuji homogenitasnya menggunakan Levene's Test. Selanjutnya untuk mengetahui ada tidaknya pengaruh perlakuan terhadap tunas yang muncul, maka data jumlah dan panjang tunas dianalisis menggunakan Independent sample $t$ test. Uji t untuk data yang variannya sama akan menggunakan rumus:

$$
t=\frac{\bar{x}_{1}-\bar{x}_{2}}{\sqrt{\frac{\left(\mathrm{n}_{1}-1\right) \mathrm{S}_{1}^{2}+\left(\mathrm{n}_{2}-1\right) \mathrm{S}_{2}^{2}}{\mathrm{n}_{1}+\mathrm{n}_{2}-2}\left(\frac{1}{\mathrm{n}_{1}}+\frac{1}{n_{2}}\right)}}
$$

Uji t untuk data yang variannya tidak sama akan menggunakan rumus:

$$
t=\frac{\bar{x}_{1}-\bar{x}_{2}}{\sqrt{\frac{S_{1}^{2}}{n_{1}}+\frac{S_{2}^{2}}{n_{2}}}}
$$

Keterangan :

$\mathrm{n}_{1} \quad=$ Jumlah sampel 1

$\mathrm{n}_{1} \quad=$ Jumlah sampel 2

$\bar{x}_{1} \quad=$ Rata-rata sampel ke-1

$\bar{x}_{2} \quad=$ Rata-rata sampel ke-2

$S_{1}^{2} \quad=$ Rata-rata sampel ke-1

$S_{2}^{2} \quad=$ Rata-rata sampel ke-2

Jika t hitung $>\mathrm{t}$ tabel atau (-) $\mathrm{t}$ hitung $<(-) \mathrm{t}$ tabel, maka perlakuan panjang pangkasan mempengaruhi jumlah tunas dan panjang tunas yang muncul.

\section{HASIL DAN PEMBAHASAN}

Uji varian menunjukkan hasil yang berbeda nyata terhadap jumlah tunas yang dihasilkan dari 2 perlakuan tinggi pangkasan. Hal ini terlihat dari nilai signifikansinya yang lebih rendah dari 0,05 yaitu 0,001 (Tabel 1). Hasil berbeda nyata ini dapat diartikan bahwa varian jumlah tunas antara dua perlakuan berbeda.

Hasil pengujian selanjutnya yaitu uji t terhadap parameter jumlah tunas dan panjang tunas. Uji t terhadap jumlah tunas menunjukkan nilai thitung adalah negatif (-) 5,679 lebih kecil dari t tabel yaitu -1,964 (Tabel 2). Hal ini menunjukkan perlakuan tinggi pangkasan mempengaruhi perbedaan jumlah tunas ratarata yang muncul. Nilai negatif menunjukkan bahwa nilai jumlah tunas rata-rata pada perlakuan ke-2 lebih tinggi dibandingkan jumlah tunas dari perlakuan ke-1. Jumlah tunas rata-rata yang dihasilkan setelah 4 bulan pemangkasan pada tinggi pangkasan $20 \mathrm{~cm}$ yaitu 2,59 tunas lebih tinggi dibandingkan tinggi pangkasan $10 \mathrm{~cm}$ yaitu 2,11 tunas (Gambar 1). Hasil ini sama dengan hasil penelitian Mashudi \& Susanto (2013) pada tanaman meranti tembaga, dimana tinggi pangkasan $80 \mathrm{~cm}$ menghasilkan jumlah tunas terbanyak dibandingkan tinggi pangkasan 20, 40 dan $60 \mathrm{~cm}$. 
Tabel 1. Hasil uji varian perlakuan tinggi pangkasan terhadap jumlah tunas dan panjang tunas Bidara Laut umur 4 bulan

Table 1. Result of variant test of height of hedging treatments on number of shoots and length of shoots of Strychnos lucida at 4 month old

\begin{tabular}{ccccc}
\hline $\begin{array}{c}\text { Sumber variasi } \\
\text { (Source of variation) }\end{array}$ & \multicolumn{2}{c}{$\begin{array}{c}\text { Jumlah Tunas } \\
\text { (Number of shoots) }\end{array}$} & \multicolumn{2}{c}{$\begin{array}{c}\text { Panjang Tunas } \\
\text { (Length of shoots) }\end{array}$} \\
\cline { 2 - 5 } & $\mathrm{F}$ & $\mathrm{Sig}$ & $\mathrm{F}$ & Sig \\
\hline $\begin{array}{c}\text { Tinggi pangkasan } \\
\text { (Height of hedging) }\end{array}$ & $10,786^{*}$ & $0,001^{*}$ & $3,314^{\mathrm{ns}}$ & $0,069^{\mathrm{ns}}$ \\
\hline
\end{tabular}

Keterangan (Remarks): * = berbeda nyata pada taraf 5\% (significantly at 5\% level); $\mathrm{ns}=$ tidak berbeda nyata $($ not significantly)

Pemangkasan tanaman bidara laut pada tinggi pangkasan yang lebih tinggi, memproduksi tunas lebih banyak karena kemampuan bertunas pada tiap mata tunas sama sehingga semakin panjang batang utama maka semakin banyak tunas yang akan muncul. Hal ini sejalan dengan hasil penelitian yang dilakukan oleh Putri dan Ristiyana (2006). Selain itu semakin panjang batang ada kemungkinan nutrisi yang tersedia lebih banyak, sehingga tunas yang dihasilkan akan semakin banyak dibandingkan tanaman yang pangkasannya lebih pendek (Mashudi \& Susanto, 2013).
Faktor lain yang mempengaruhi banyaknya tunas yang muncul pada tanaman yang dipangkas adalah auksin. Auksin adalah hormon di dalam tanaman yang berfungsi untuk merangsang pertumbuhan jaringanjaringan tanaman seperti merangsang pertunasan (Djamhari, 2010). Batang yang lebih panjang pada tinggi pangkasan $20 \mathrm{~cm}$ biasanya mengandung auksin lebih banyak dibandingkan tinggi pangkasan $10 \mathrm{~cm}$. Hal ini kemungkinan yang menyebabkan jumlah tunas yang dihasilkan pada batang yang lebih panjang lebih banyak dibandingkan batang yang lebih pendek.

Tabel 2. Hasil uji t jumlah tunas dan panjang tunas Bidara Laut umur 4 bulan terhadap perlakuan tinggi pangkasan

Table 2. T-test result of number of shoots and length of shoots of Strychnos lucida at 4

\begin{tabular}{lcc}
\hline & $\begin{array}{c}\text { Jumlah Tunas } \\
(\text { Number of shoots })\end{array}$ & $\begin{array}{c}\text { Panjang Tunas } \\
\text { (Length of shoots) }\end{array}$ \\
\hline Nilai t hitung (Values of $t$-statistic) & $-5,679$ & 4,844 \\
Nilai t tabel (Value of $t$-table) & $-1,964$ & 1,964 \\
\hline
\end{tabular}

Hasil uji varian terhadap panjang tunas rata-rata yang dihasilkan menunjukkan hasil yang berkebalikan dari hasil uji varian terhadap jumlah tunas. Dari uji varian yang dilakukan, menunjukkan bahwa nilai signifikansi lebih dari 0,05 (Tabel 1). Hal ini berarti bahwa varian panjang tunas yang dihasilkan dari perlakuan tinggi pangkasan adalah sama (homogen).

Pengujian pengaruh perlakuan tinggi pangkasan terhadap panjang tunas menunjukkan bahwa terdapat perbedaan panjang tunas rata-rata. Hal ini ditunjukkan dengan nilai t hitung $(4,844)$ yang lebih besar dari $t$ tabel $(1,964)$ (Tabel 2). Hasil ini menunjukkan bahwa perlakuan tinggi pangkasan mempengaruhi panjang tunas yang dihasilkan. Oleh karena nilai t hitung positif dapat diartikan panjang tunas perlakuan 
pertama (tinggi pangkasan $10 \mathrm{~cm}$ ) lebih tinggi dibandingkan perlakuan kedua (tinggi pangkasan $20 \mathrm{~cm}$ ). Hal ini terlihat dari panjang tunas rata-rata yang dihasilkan dari kedua perlakuan (Gambar 1). Pada tinggi pangkasan $10 \mathrm{~cm}$, panjang tunas rata-ratanya mencapai $8,99 \mathrm{~cm}$, sedangkan panjang tunas pada tinggi pangkasan $20 \mathrm{~cm}$ sebesar $6,65 \mathrm{~cm}$.

Adanya pengaruh perlakuan tinggi pangkasan di kebun pangkas terhadap panjang tunas yang dihasilkan juga terlihat pada beberapa hasil penelitian. Hasil penelitian Mashudi et al. (2008) pada tanaman pulai menunjukkan hasil yang sama dengan penelitian ini, dimana tinggi tunas yang terbaik terlihat pada tinggi pangkasan yang lebih rendah $(20 \mathrm{~cm})$ dibandingkan tinggi pangkasan lainnya (30 dan $40 \mathrm{~cm}$ ).

Hasil penelitian Pramono \& Danu (2013) juga menunjukkan adanya pengaruh perlakuan tinggi pangkasan terhadap panjang tunas, akan tetapi hasilnya berkebalikan. Tinggi pangkasan yang lebih tinggi $(90 \mathrm{~cm})$ justru menghasilkan panjang tunas yang terbaik dibandingkan tinggi pangkasan 30 dan $60 \mathrm{~cm}$. Penelitian lain justru menunjukkan perlakuan tinggi pangkasan pada tanaman ganitri dan tanaman meranti tembaga tidak memiliki pengaruh yang nyata terhadap panjang tunas yang dihasilkan (Rohandi, 2013; Mashudi \& Susanto, 2013).

Pemangkasan tajuk tanaman yang dilakukan pada pemangkasan di kebun pangkas akan membantu distribusi auksin ke seluruh bagian tanaman termasuk tunas lateral. Hal inilah yang menyebabkan terjadinya perkembangan tunas lateral pada tanaman yang dipangkas (Mashudi \& Susanto, 2013). Perbedaan tinggi pangkasan akan mempengaruhi distribusi auksin ke seluruh bagian tanaman. Semakin mendekati bagian apikal tanaman (bagian tajuk yang dipangkas), maka jumlah auksin akan semakin sedikit (Heddy, 1989 dalam Mashudi \& Susanto, 2013).

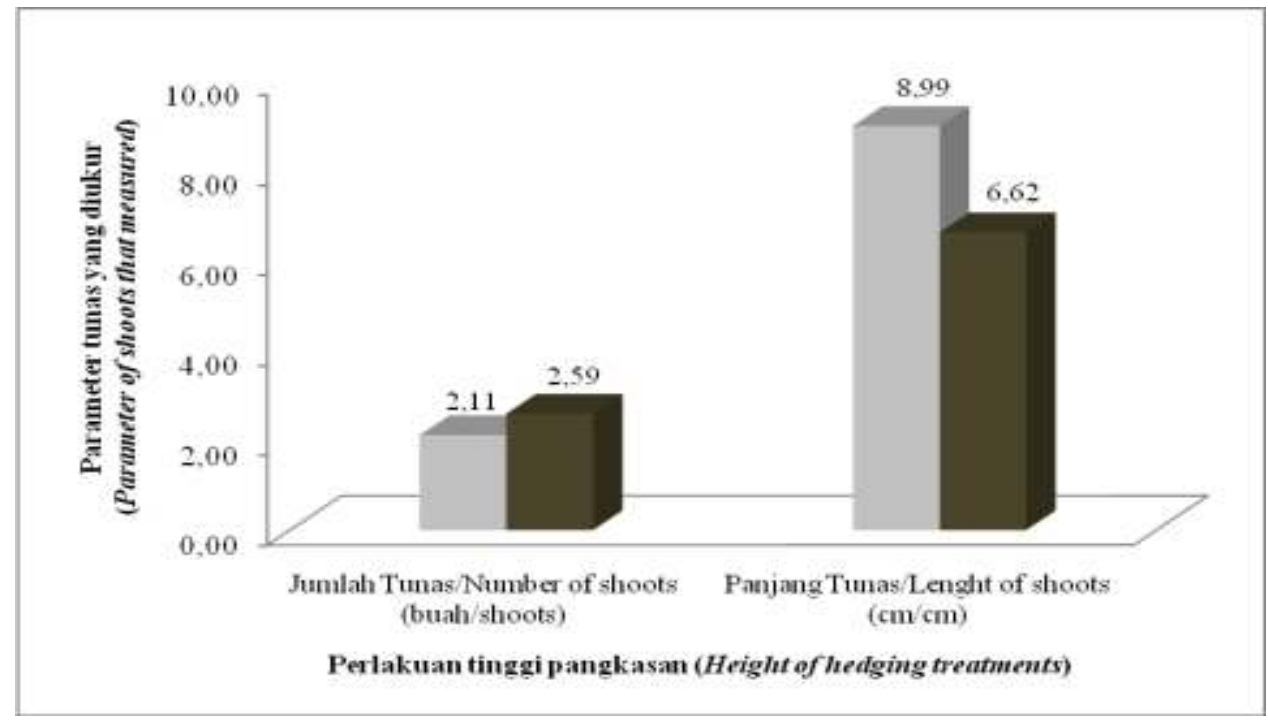

Keterangan (Remarks):

- Tirfgi pangkasan $20 \mathrm{~cm}$ (Height of hedging $20 \mathrm{~cm}$ )

- Tirggi pangkasan $10 \mathrm{~cm}$ (Height of hedging $10 \mathrm{~cm}$ )

Gambar 1. Rata-rata jumlah tunas dan panjang tunas Bidara Laut pada perlakuan tinggi pangkasan di kebun pangkas

Figure 1. Average of number of shoots and length of shoots of Strychnos lucida at height of hedging treatments on hedge orchard 
Jika dilihat dari tunas yang dihasilkan dari kedua perlakuan tinggi pangkasan terlihat pada stek yang menghasilkan banyak tunas, rata-rata panjang tunasnya lebih pendek dibandingkan stek yang menghasilkan sedikit tunas. Hal ini dimungkinkan karena unsur hara dengan jumlah sama akan lebih optimal mendukung pertumbuhan tunas pada tanaman dengan jumlah tunas yang sedikit dibandingkan tanaman dengan tunas yang lebih banyak (Pramono \& Danu, 2013).

Jumlah tunas bidara laut yang dihasilkan dari teknik pemangkasan di kebun pangkas umur 4 bulan terbilang sedikit (di bawah 3 tunas). Hal ini dimungkinkan karena umur tanaman induk (stock plant) masih tergolong muda yaitu 1,5 tahun. Nurhasybi et al. (2007) menyatakan kemampuan kebun pangkas untuk menghasilkan jumlah tunas yang optimal tergantung dari umur stock plant. Hal lain yang mungkin berpengaruh terhadap sedikitnya tunas yang dihasilkan dari kebun pangkas bidara laut adalah kecepatan tumbuh dari tanaman bidara laut yang tergolong lambat. Hasil penelitian Rahayu \& Wahyuni (2014) menunjukkan pertumbuhan tunas pada stek batang bidara laut umur 4 bulan, pertambahan panjangnya hanya berkisar $1,18-5,10 \mathrm{~cm}$ dan pertambahan diameternya $0,07-0,53 \mathrm{~mm}$.

\section{KESIMPULAN}

Tinggi pangkasan pada tanaman di kebun pangkas bidara laut berpengaruh nyata terhadap tunas yang dihasilkan dengan nilai signifikansi 0,001 , sedangkan panjang tunas tidak signifikan pada perlakuan tinggi pangkasan yang berbeda $(>0,05)$. Setelah 4 bulan pemangkasan, tinggi pangkasan $20 \mathrm{~cm}$ dari permukaan tanah di dalam polibag menghasilkan jumlah tunas yang lebih banyak dibandingkan tinggi pangkasan $10 \mathrm{~cm}$.

\section{UCAPAN TERIMA KASIH}

Kami ucapkan terima kasih yang sebesarbesarnya kepada Gipi Samawandana, selaku teknisi dalam tim penelitian ini dan semua pihak yang telah membantu sehingga penelitian ini dapat terlaksana.

\section{DAFTAR PUSTAKA}

Djamhari, S. (2010). Memecah dormansi rimpang temulawak (Curcuma xanthorrhiza Roxb) menggunakan larutan atonik dan stimulasi perakaran dengan aplikasi auksin. Jurnal Sains dan Teknologi Indonesia 12(1), 66-70.

Hasan, R. A., Nandini, R., \& Wahyuni, N. (2011). Kajian Pemanfaatan Tanaman Bidara Laut (Strychnos lucida) oleh Masyarakat di Kabupaten Dompu dan Buleleng. Prosiding Workshop: Sintesa Hasil Penelitian Hutan Tanaman (pp. 353-358). Bogor: Pusat Litbang Peningkatan Produktivitas Hutan.

Hidayat, A., \& Nurohman, E. (2016). Pengaruh Ukuran Diamater Stek Batang Hopea odorata Roxb. Dari Kebun Pangkas Terhadap Kemampuan Bertunas, Berakar Dan Daya Hidupnya.. Jurnal Penelitian Hutan dan Konservasi Alam, 4(1), 1-12.

Mashudi, Adinugraha, H., Setiadi, D., \& Ariani, A. (2008). Pertumbuhan Tunas Tanaman Pulai pada Beberapa Tinggi Pangkasan dan Dosis Pupuk NPK. Jurnal Pemuliaan Tanaman Hutan 2 (2) , 211-220.

Mashudi, \& Susanto, M. (2013). Kemampuan Bertunas Stool Plants Meranti Tembaga (Shorea leprosula Miq.) dari Beberapa Populasi di Kalimantan. Jurnal Pemuliaan Tanaman Hutan 7(2), 119132.

Nurhasybi, Sudrajat, D., Pramono, A., \& Budiman, B. (2007). Review status iptek perbenihan tanaman hutan. Publikasi khusus Vol VI No.6. Bogor: Bala Penelitian Teknologi Perbenihan Bogor.

Pramono, A., \& Danu. (2013). Pengaruh pemangkasan dan pelengkungan 
terhadap produktivitas tunas pada pohonpangkas kayu bawang (Azadirachta excelsa). Jurnal Perbenihan Tanaman Hutan 1(2), 93-101.

Priadjati, A., Smits, W., \& Tolkamp, G. (2001). Vegetative Propagation to Assure a Continous Supply of Plant Material for Forest Rehabilitation. In: P.J.M. Hillegers \& H.H. de Iongh (eds.), The balance between biodiversity conservation and sustainable use of tropical rain forests. (pp. 19-29). Wageningen: Tropenbos.

Pudjiono, S. (2014). Produksi bibit jati unggul (Tectona grandis L.F.) dari klon dan budidayanya. Bogor: IPB Press.

Putri, K., \& Ristiyana, A. (2006). Kemampuan Pertunasan Tanaman Merbau (Intsia bijuga O. Ktza) Umur 6 Tahun. Prosiding: Seminar Hasil-Hasil
Penelitian Balai Litbang Teknologi Perbenihan (pp. 99-101). Bogor: Pusat Penelitian dan Pengembangan Hutan Tanaman.

Rahayu, A., \& Wahyuni, R. (2014). Pengaruh Media Tanam Organik terhadap Pertumbuhan Stek Batang Bidara Laut (Strychnos lucida R Brown). Prosiding: Seminar Nasional Silvikultur Ke-2 (pp. 615-620). Yogyakarta: Universitas Gadjah Mada.

Rohandi, A. (2013). Pengaruh tinggi pangkasan terhadap produksi tunas pada kebun pangkasan ganitri. Prosiding Seminar Nasional Agroforestri (pp. 741-746). Malang: Balai Penelitian Teknologi Agroforestry, Fakultas Pertanian Universitas Brawijaya, ICRAF dan Masyarakat Agroforestri Indonesia. 
Jurnal FALOAK Vol.1 No. 1 April $2017:$ 31-38 